\title{
Audiological evaluation following snake bite - Case Report
}

\author{
Govindaraj S. ${ }^{1}$, Arivazhagan G.B. ${ }^{2}$, Jinsha A. ${ }^{3}$, Swetha Lakshmi M. ${ }^{4}$ \\ ${ }^{1}$ Dr. Sriram Govindaraj, Assistant Professor, ${ }^{2}$ Dr. Ganesh Bala Arivazhagan, Associate Professor, ${ }^{3}$ Dr. Jinsha A, \\ Postgraduate, ${ }^{4}$ Dr. Swetha Lakshmi M., Postgraduate, all authors are affiliated with Department of Otorhinolaryngology, \\ Vinayaka Mission's Medical College, Vinayaka Mission Research Foundation, DU, Keezhakasakudi, Karaikal, Chennai, \\ India.
}

Corresponding Author: Dr. Sriram Govindaraj, Assistant Professor, Department of Otorhinolaryngology, Vinayaka Mission's Medical College, Vinayaka Mission Research Foundation, DU, Keezhakasakudi, Karaikal. E-mail: rushh2jinu@gmail.com

\begin{abstract}
We are reporting a case with hearing loss following krait snake bite. Case was diagnosed as snake bite and treated in the emergency department and after stabilising she was referred to the oto-rhinolaryngology department for evaluation of sudden hearing loss. Audiological evaluation was carried out to identify degree, type of hearing loss and site of lesion. Puretone audiometry showed bilateral moderate sensory neural hearing loss. The diagnosis was confirmed with Transient evokedotoacoustic emissions and Click evoked auditory brainstem response testing. From the above audiological tests it is evident that the snake bite victim has cochlear hearing loss. This could be due to the venom carried away from the wound by the lymphatics and then is circulated by the blood stream throughout the body.
\end{abstract}

Key words: Snakebite, Audiological evaluation, Puretone audiometry

\section{Introduction}

On June 9th, 2017 WHO categorized snakebite envenomation into the Category A of the Neglected Tropical Diseases. Rural populationare the major victims of snake bites. Hearing lossis a rare symptom followed by snake bite[1]. Only few cases on hearing loss following snake bite are reported in the literature $[2]$.

The venom of Bungaruscaeruleus (krait) contains a mixture of alpha, beta-bungarotoxin and caerulotoxin. Alpha-bungarotoxins cause failure of neuromuscular transmissionby binding to post synaptic nAchR at neuromuscular junction, Beta-bungarotoxins arepresynaptically active neurotoxic phospholipases. Exposureto these toxins causes the failure of neuromuscular transmission and depletion ofsynaptic vesicles from the nerve terminal.

Caerulotoxins a minor component of the venom and is found exclusively inkraits and are structurally similar to alpha-bungarutoxins. Alphabungarutoxin and caerulotoxin acts on post synaptic membrane [2].

\section{Case Presentation}

48 year old female patient came to ENT Departmentfor hearing loss evaluation following snake bite;she was treated in the emergency department for snake bite andidentified the snake to be krait.She was referred to the Department ofOtorhinolaryngology following her complaints of reduced hearing sensitivity and ear fullness. History revealed that patientwas having normal hearing before snake bite and there was no history of ear discharge. Otoscopic examination revealed normal ear canal with intact tympanic membrane onboth ears.Hearing assessment was carried out using audiological examination. Routine pure tone audiometry was done to check theair conduction and bone conduction thresholds of the patient.Impedanceaudiometry was done to rule out any middle ear pathology. Otoacoustic emissions test was performedto check the function of outer hair cells. Auditorybrainstem responses (ABR) were done to rule out the presence of retro cochlear pathology.

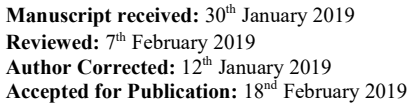


Pure tone audiometry shows bilateral moderate sensorineural hearing loss with pure tone average of $41.6 \mathrm{dBHL}$ in right ear and $43.3 \mathrm{dBHL}$ in left ear. Impedance audiometry shows 'A' type tympanogram showing no middle ear pathology. Both ears ipsilateral and contralateral acoustic reflex absent.

Auditory brainstem responses reveal that there is no auditory nerve dysfunction in both ears as the interpeak latencies and the interaural latencies are observed to be within normal limits. Results of Transient Evoked Otoacoustic Emission reveals absentotoacoustic emissions bilaterally.

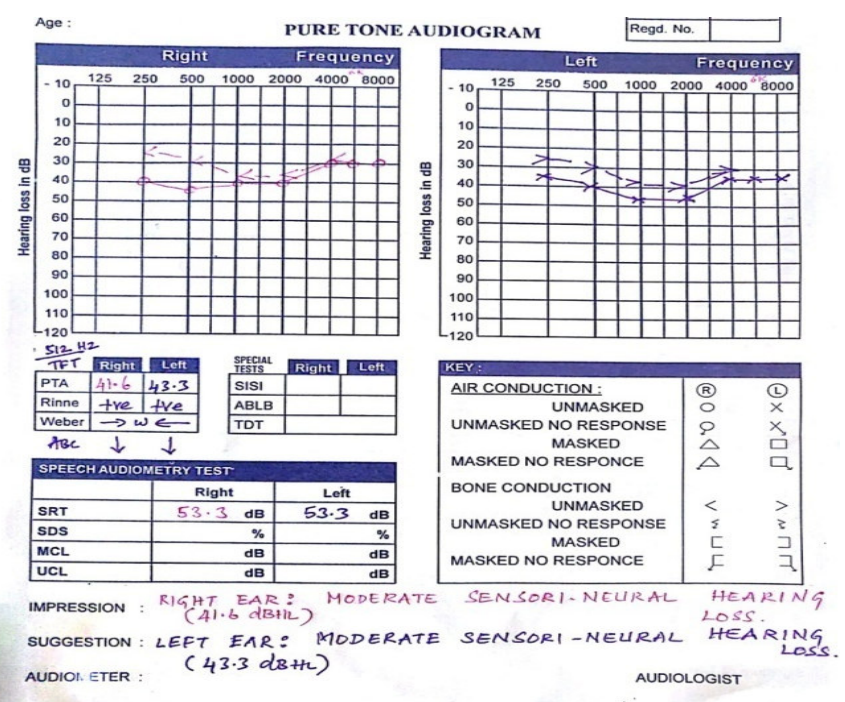

Figure-1: Shows results of pure tone audiometry

Figure 1.1 shows results of pure tone audiometry

Pure tone audiometry shows bilateral moderate sensorineuralhearing loss

Pure tone average:

Right ear:41.6 dBHL

Left ear:43.3 dBHL
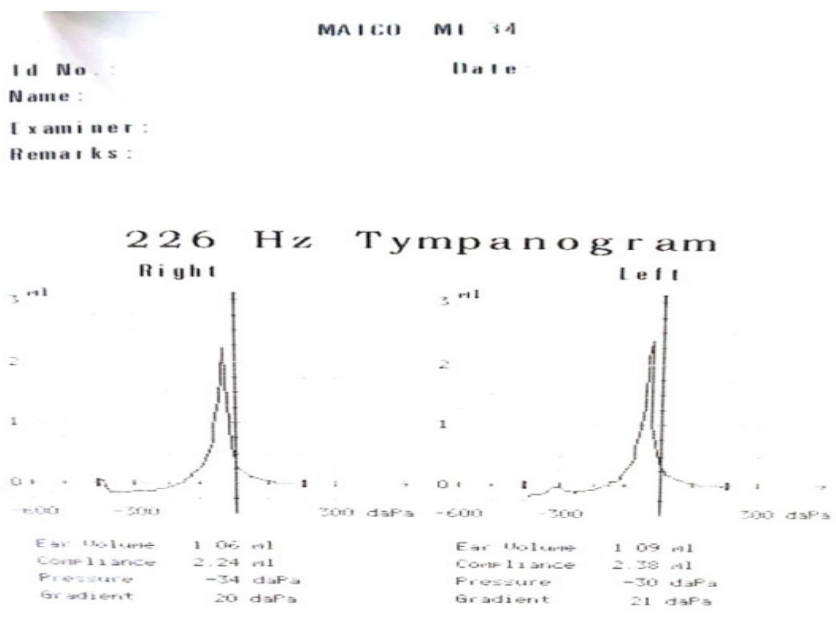

Figure-2: Shows impedance audiometry results of the patient

Impedence audiometry shows ' $A$ ' type tympanogram showing nomiddle ear pathology. 


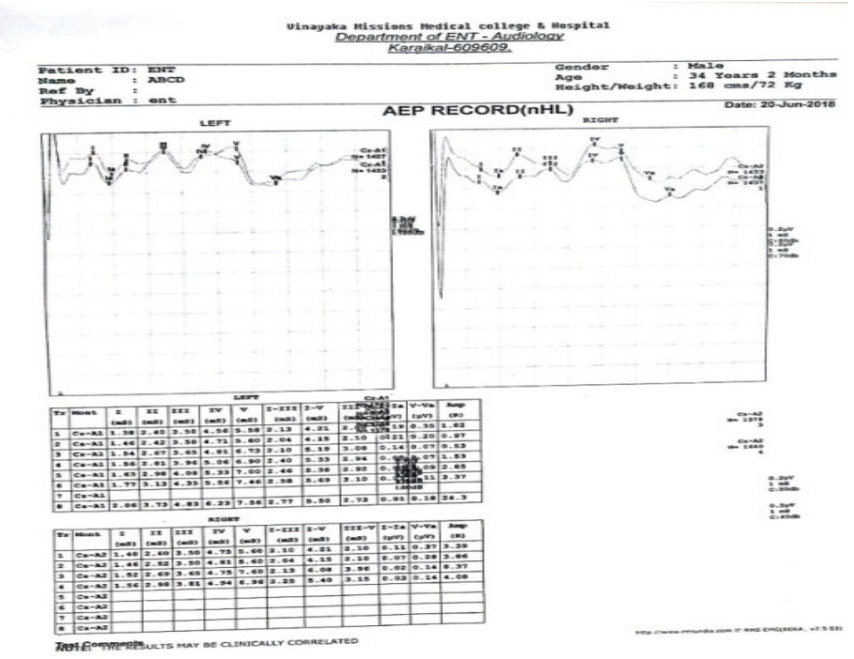

Figure-3: Shows auditory brainstem responses of the patient

Auditory brainstem responses reveals that there is no auditory nerve dysfunctionin both ears as the interpeak latencies and the interaural latencies are observedto be within normal limits.

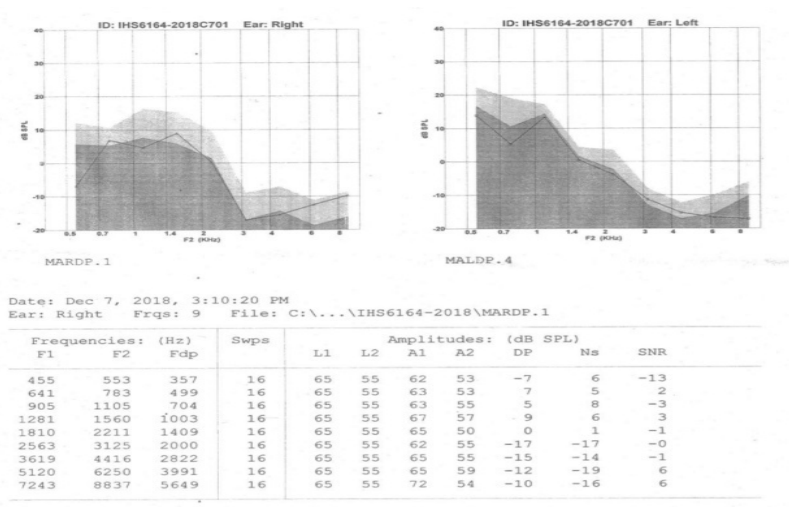

Figure-4: Shows transient evoked otoacoustic emissions ofthe patient

Results of Transient Evoked Otoacoustic Emission reveals absentotoacoustic emissions bilaterally

\section{Discussion}

Sudden bilateral hearing loss following snake bite has been reported by Sabharwal R.K, Sanchetee P.C, Sethi P.K, Gaudi S.C [5]. Documentation of hearing loss in a case with krait snake bite in the literature is rare [1]. We are reporting a case with amoderate degree of sensorineural hearing loss caused by cochlear damage due to snake bite.

Aftersnake bite venom quickly spreads throughout the body, is carried away from thewound by the lymphatics and then is circulated by the bloodstream and results in cochlear damagealso [2]. The venom which is carried away by the bloodstream could have damaged the hair cells of the cochlea whichis been proved in the transient evoked otoacoustic emissionstest that there has been dysfunction in the cochlear hair cells. Pure tone audiometry shows bilateral moderate sensorineural hearing loss with pure tone average of $41.6 \mathrm{dBHL}$ in right ear and $43.3 \mathrm{dBHL}$ in left ear. Impedance audiometry shows ' $A$ ' type tympanogram showing no middle ear pathology. Both ears ipsilateral and contralateral acoustic reflex absent.

Auditory brainstem responses reveals that there is no auditory nerve dysfunction in both ears as the interpeak latencies and the interaural latencies are observed to be within normal limits.

Results of Transient Evoked Otoacoustic Emission reveals absent otoacoustic emissions bilaterally. 
Also there is a possibility of having pre-synaptic orpostsynaptic hearing loss which must be ruled out in individuals. The venom of Bungaruscaeruleus (krait) containsa mixture of alpha, beta-bungarotoxin and caerulotoxin [3].

Alpha-bungarotoxins cause failure of neuromuscular transmission by binding to post synaptic nAchR at neuromuscular junction; Beta-bungarotoxins contains $20 \%$ protein content of thevenom and are most toxic components of the venom.

They are pre-synaptically active neurotoxic phospholipases [2]. Exposure to these toxins in vivo and in vitro causes the failure of neuromusculartransmission for two to three hours and depletion ofsynaptic vesicles from the nerve terminal boutons.

Caerulotoxinis a minor component of the venom are found exclusively inkraits and are structurally similar to alpha-bungarutoxins. Alphabun-garutoxin and caerulotoxin acts on post synaptic membrane [3].

\section{Conclusion}

We tried to emphasize that any patients with history of snake bite should undergo hearing evaluation. Allotorhinolaryngologists should be aware to elicit history of snakebite as a remote cause for sensorineural hearing loss.

In our casethe victim of snake bite - krait has confirmed cochlear hearing loss which could be due to the impairment of outer hair cell function. Based on above observations we recommend all cases of snake bite should undergoaudiological evaluation - pure tone audiometry, impedance audiometry, otoacoustic emissions and auditory brainstem responsewhich would help in early diagnosis and treatment of hearing loss.

\section{Funding: Nil, Conflict of interest: Nil}

Permission from IRB: Yes

\section{References}

1. Kularatne SA. Common krait (Bungarus caeruleus) bite in Anuradhapura, Sri Lanka: a prospective clinical study, 1996-98. Postgrad Med J. 2002 May;78(919): 276-80.

2. Russell FE: Snake venom poisoning. Schloium Int 3: 256,1983

3. Bon C, Changeux JP. Chemical and pharmacological characterization of toxic polypeptides from the venom of Bungarus caeruleus. Eur J Biochem. 1977 Mar 15;74 (1):31-42.

4. Roeser RJ, Michael Valente, Dunn HH: Audiology Diagnosis 2:436, 2007

5. Sabharwal RK, Sanchetee PC, Sethi PK, et al. Sudden bilateral deafness following snake bite. J Assoc Physicians India. 1987 Oct;35(10):735-6.

6. Warrell DA. Injuries, envenoming, poisoning, and allergic reactions caused by animal. In: Warrell DA, Cox TN, Firth JD, Benj J Jr, editors. Oxford Textbook of Medicine. Oxford: Oxford University Press; 2003. pp. $923-45$.

7. Fernando P, Dias S. Indian krait bite poisoning. Ceylon Med J. 1982 Mar;27(1):39-41.

8. Prasad K, Singh B, Khan SA, Agarwala AK, et al. A case of bite by Krait snake. J Assoc Physicians India. 1979 Nov;27(11):1043-4.

9. Fernando P, Dias S. Indian krait bite poisoning. Ceylon Med J. 1982 Mar;27(1):39-41.

10. Thomas PP, Jacob J. Randomised trial of antivenom in snake envenomation with prolonged clotting time. $\mathrm{Br}$ Med J (Clin Res Ed). 1985 Jul 20;291(6489):177-8.

\section{How to cite this article?}

Govindaraj S., Arivazhagan G.B., Jinsha A., Swetha Lakshmi M. Audiological evaluation following snake bite- Case Report. Trop J Ophthalmol Otolaryngol.2019;4(1):26-29.doi:10.17511/jooo.2019.i01.05 